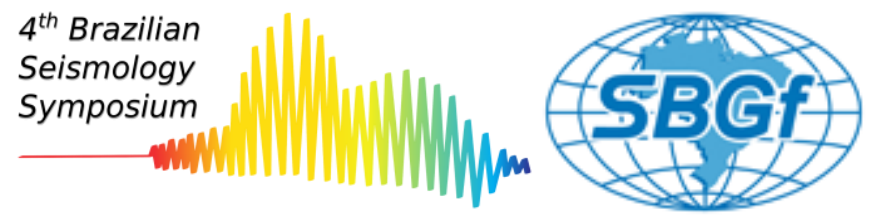

\title{
The New Infrasound Station of South America, IS01-Pilcaniyeu, Argentina
}

\author{
Victor Fontenele Carvalho ${ }^{1}$ Pavel Martysevich ${ }^{2}$ Juraci Carvalho
}

1) Enki Engineering Solutions, 2) Comprehensive Nuclear-Test-Ban Treaty Organization, 2) Seismological Observatory University of Brasilia.

Copyright 2021, SBGf - Sociedade Brasileira de Geofísica.

This paper was prepared for presentation during the $17^{\text {th }}$ International Congress of the Brazilian Geophysical Society held in Rio de Janeiro, Brazil, $16-19$ August 2021.

Contents of this paper were reviewed by the Technical Committee of the $17^{\text {th }}$ International Congress of the Brazilian Geophysical Society and do not necessarily represent any position of the SBGf, its officers or members. Electronic reproduction or storage of any part of this paper for commercial purposes without the written consent of the Brazilian Geophysical Society is prohibited.

\section{Abstract}

The IMS Infrasound network at South America is composed of 10 stations, 2 in Argentina, 2 in Chile, 2 UK stations, 1 in Paraguay, 1 in Brazil, 1 in Bolivia and 1 in the island of Galapagos, Ecuador. At the present time, they are all installed, certified and running. As per the number of elements they are very heterogeneous ranging from 4 elements up to 8 elements.

The last infrasound station implemented was the IS01 Pilcaniyeu, Argentina located in the vicinity of the Picaniyeu town, municipality of Rio Negro Argentina. The region climate has a cold winter, arid and continental. The station is composed of a Central Recording Facility (CRF) and eight array elements, $\mathrm{H} 1$ through $\mathrm{H} 8$. Each element has a Wind Noise Reduction System (WNRS) of 18-m diameter (96 inlet ports). They are spaced from 0.2 to $1.3 \mathrm{~km}$ from each other allowing the composition of several triangles ranging from 0.5 to $1.4 \mathrm{~km}$ side length, which is favorable for array data processing. The overall geometry is an irregular elongated shaped form with about $1.5 \mathrm{~km} \mathrm{EW}$ and $0.75 \mathrm{~km} \mathrm{NS}$ and the central element coordinates are $41.11^{\circ} \mathrm{S} 70.72^{\circ} \mathrm{W}$, elevation 994 $\mathrm{m}$. The array response is almost the optimal that can be achieved with the proposed number of elements and configuration.

Each element has a protective fence and gate, a stable power system, data acquisition unit (digitizer), a fibre optic communication modem and two microbarometers. The central element $\mathrm{H} 1$ has in addition a meteorological station to record the wind speed and direction, temperature, and absolute pressure.

One of the microbarometers at each array element, MB3a with a flat response from 0.01 to $28 \mathrm{~Hz}$, is connected to the Wind Noise Reducing System, and the other microbarometer (MB2005) is connected to a reference inlet port. The Infrasound data acquisition elements are connected to the CRF via fiber optic communication system and the infrasound data is transmitted to the International Data Center (the "IDC") in Vienna, Austria, through the Global Communication Infrastructure (CGI).

The station performance is alike the stations without vegetation shield showing periods of high and low noise directly related to the wind speed. The quiet period, low wind condition, shows that the station can be very efficient almost as good as the "Low Noise Model". Some of the station detections show a majority of signals with low frequency forming PMCC families from southeast direction, probably related to the microbaroms from the South Atlantic Ocean. 